\title{
Pronounced Cellular Diversity and Extrasynaptic Location of Nicotinic Acetylcholine Receptor Subunit Immunoreactivities in the Chicken Pretectum
}

\author{
Erik M. Ullian and Peter B. Sargent \\ Neuroscience Graduate Program and Departments of Stomatology and Physiology, University of California, San \\ Francisco, California 94143
}

\begin{abstract}
The diversity of nicotinic ACh receptor (AChR) expression in the chick lateral spiriform nucleus ( $\mathrm{SpL}$ ) was assessed using subunit-specific monoclonal antibodies (mAbs) and laser scanning confocal microscopy. The late embryonic $\mathrm{SpL}$ was immunoreactive for mAbs against the $\alpha 2, \alpha 5, \alpha 7$, $\alpha 8$, and $\beta 2$ AChR subunits. Distinct neuronal cell classes were determined using pair-wise staining of mAbs. Approximately $90 \%$ of the neurons in the SpL contained both $\alpha 5$-like immunoreactivity (LI) and $\beta 2-L I$, with no neurons having only one of these subunit-LIs. Approximately $70 \%$ of the neurons contained $\alpha 2-\mathrm{LI}$. All $\alpha 2-\mathrm{LI}$ neurons contained $\alpha 5 / \beta 2-\mathrm{LI}$; thus, neurons having $\alpha 2-\mathrm{LI}$ are a subset of those having $\alpha 5$ - and $\beta 2-\mathrm{Ll}$. Fewer neurons, approximately $20 \%$, contained $\alpha 7-$ LI. A subset of $\alpha 7$-positive neurons were immunoreactive for other subunits; for example, some $\alpha 7$-positive neurons also contained $\alpha 2$-LI. Fewer than $15 \%$ of the neurons contained $\alpha 8$-LI. Some of the $\alpha 8-\mathrm{LI}-$ containing neurons contained $\alpha 7$-LI. The 14 week posthatch SpL resembles the late embryonic nucleus in the percentage of neurons immunoreactive for $\alpha 2, \alpha 5, \alpha 7, \alpha 8$, and $\beta 2 \mathrm{AChR}$ subunits, and in the presence of multiple classes based on AChR subunit immunoreactivity. In addition, $\alpha 4-$ LI was found in about $20 \%$ of the 14 week SpL neurons. Double-label immunofluorescence experiments with mAbs to AChRs and to synaptic vesicle antigens showed that most clusters of $\alpha 5-\mathrm{LI}$ and $\beta 2-\mathrm{LI}$ are extrasynaptic. The pronounced diversity of $A C h R$ subunit expression and the extrasynaptic location of AChR-LI suggest that AChR-like molecules in the SpL do not function solely to respond to transmitter focally released from presynaptic terminals.
\end{abstract}

[Key words: nicotinic ACh receptors, extrasynaptic, diversity, optic tectum, nucleus spiriformis lateralis, chicken brain]

Nicotinic ACh receptors (AChRs) are well-characterized members of a supergene family of ligand-gated channels that include glycine receptors, $\mathrm{GABA}_{\mathrm{A}}$ receptors, and $5-\mathrm{HT}_{3}$ receptors. Mus-

\footnotetext{
Received Apr. 24, 1995; revised June 14, 1995; accepted June 19, 1995

We thank Dr. J. M. Lindstrom (U. Pennsylvania), Dr. D. K. Berg (UC San Diego), and Dr. S. Carlson (U. Washington) for antibodies; Dr. J. M. Lindstrom, Dr. H. Karten, and Dr. C. D. Weaver, and members of the Sargent lab for reviewing a draft of this manuscript; and Gordon, James, and Suzanne for pullets. This work was supported by NIH Grants NS 24207, GM 07449 (to E.M.U.), and RR 07131

Correspondence should be addressed to Mr. Erik Ullian, Department of Physiology, University of California, San Francisco, CA 94143-0444.

Copyright $(\mathcal{C} 1995$ Society for Neuroscience $0270-6474 / 95 / 157012-12 \$ 05.00 / 0$
}

cle $\Lambda \mathrm{ChRs}$ are pentamers containing four subunits in the stoichiometry $\alpha_{2} \beta \gamma($ or $\epsilon) \delta$. Muscle cells synthesize either $\alpha 1_{2} \beta 1 \gamma \delta$ or $\alpha 1_{2} \beta 1 \epsilon \delta$ receptors, depending upon their state of innervation (reviewed in Hall and Sanes, 1993). In contrast, neuronal AChRs are more diverse and are composed of several subunits derived from a family of homologous genes named $\alpha 2-\alpha 9$ and $\beta 2-\beta 4$ (Sargent, 1993; Elgoyhen et al., 1994). In the nervous system, each of the AChR subunit mRNAs is expressed in a unique subset of neurons, and some neurons express as many as six different transcripts and, presumably, proteins (reviewed in Role, 1992; Sargent, 1993). These diverse expression patterns imply that AChRs have diverse subunit compositions and functional roles.

Although the presence of AChR subunits has been demonstrated in neurons in the CNS, little is known about how these subunits are distributed within individual nuclei or whether all ncurons in a nuclcus express the same subunits. Characterizing the cellular distribution of $\mathrm{AChR}$ subunits within a nucleus containing cholinoceptive neurons would provide useful information about the functional complexity of AChRs in the CNS. Furthermore, despite the experiments cited above, there is little evidence for nicotinic AChR-mediated synaptic responses or localization of AChR subunits at synaptic sites in the CNS (Sargent, 1993). Therefore, finding AChR subunit-LI at synaptic sites would be important evidence for a classical receptor role for nicotinic AChRs in the CNS.

To study the basis and consequences of neuronal AChR diversity it is important to focus on a well-defined system where the subunits can be readily detected. The nucleus spiriformis lateralis $(\mathrm{SpL})$ in the chicken is such a system. The $\mathrm{SpL}$ is a thalamic, pretectal nucleus that receives cholinergic innervation from the semiluminaris nucleus (SLu) and projects to the optic tectum (Reiner et al., 1982; Sorenson et al., 1989). The SpL neuronal cell bodies are cholinoceptive (Sorenson and Chiappinelli, 1990) and are recognized by mAbs specific for the $\alpha 5$, $\alpha 7$, and $\beta 2$ AChR subunits (Swanson et al., 1983; Britto et al., $1992 a)$. In addition, neurons containing both $\beta 2$ - and $\alpha 7$-LI have been observed in the SpL (Britto et al., 1992b) indicating that the pattern of AChR subunit expression may be complex. We have examined the extent of this complexity by using subunitspecific anti-AChR mAbs and double-label immunofluorescence techniques. We found an extensive and unexpected diversity in AChR subunit immunoreactivities within the chick SpL nucleus. Moreover, many clusters of AChR immunoreactivity are extrasynaptic. Together, these findings raise questions about the role played by AChRs in the SpL. 


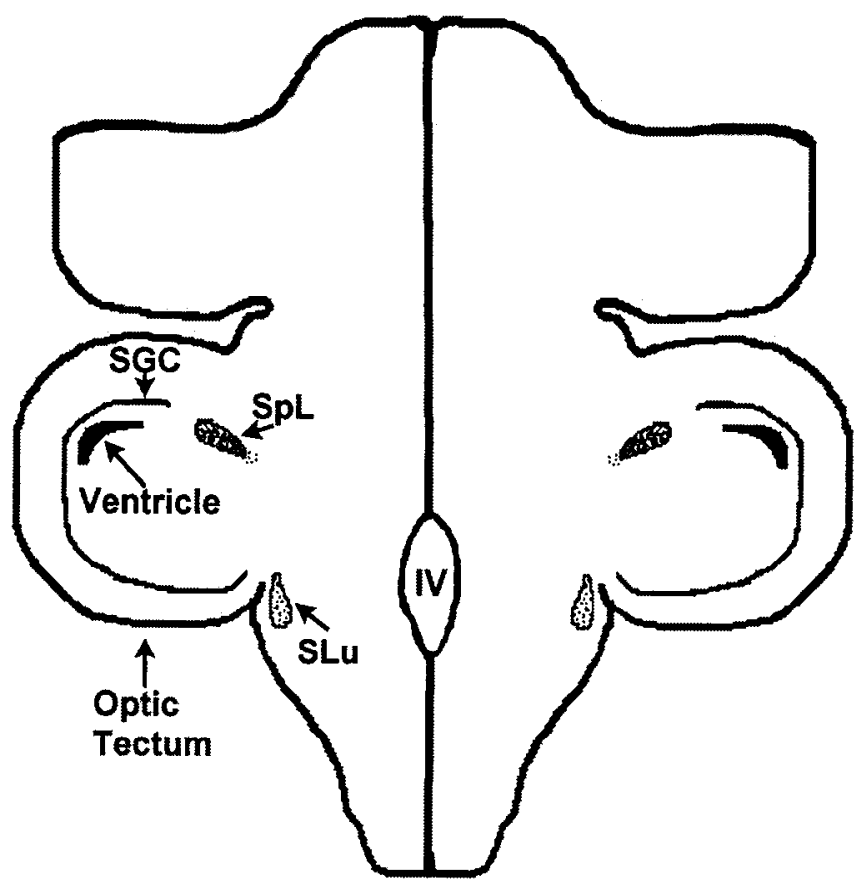

Figure 1. This schematic of a horizontal section of a chicken brain shows the location of the SpL, the SLu (which supplies the SpL with cholinergic innervation), and the SGC layer of the optic tectum (which receives innervation from the $\mathrm{SpL}$ ).

These results have been presented in abstract form (Ullian and Sargent, 1994).

\section{Materials and Methods}

Embryonic day 20-21 chicks and 12-14 week pullets (Gallus domesticus), obtained locally, were decapitated and their brains were removed and immersion-fixed in $1 \%$ formaldehyde in sodium phosphate buffer $\left(0.11 \mathrm{M}, \mathrm{pH} 7.3\right.$ ) for $1-2 \mathrm{hr}$ (embryos) or $3-5 \mathrm{hr}$ (pullets) at $4^{\circ} \mathrm{C}$. In a few instances, pullets were anesthetized and perfused with $1 \%$ formaldehyde in sodium phosphate buffer and subsequently immersion-fixed, as before. Frozen sections were prepared from brains cryoprotected in $30 \%$ sucrose in PBS $(0.015 \mathrm{M} \mathrm{NaCl}, 0.28 \mathrm{M} \mathrm{Na}$ phosphate, $\mathrm{pH} 7.3)$ and sectioned $(20 \mu \mathrm{m})$ in either coronal or horizontal planes. The sections were then mounted on gelatin-coated slides. The SpL nucleus is a pretectal nucleus located near the junction between the mesencephalon and diencephalon (Fig. 1). The nucleus, whose borders are visible in cryostat sections when viewed with dark-field optics, was identified using a stereotaxic atlas of the chick brain (Keunzal and Mason, 1988), previously published SpL immunohistochemistry (Britto et al., 1992a,b), and with the help of Dr. Harvey Karten (UC San Diego).

Rat anti-AChR mAhs 35, 268, 270, 289, 305, 318, 319, and 323 and mouse anti-AChR mAb 306 were kindly provided by Dr. Jon M. Lindstrom (University of Pennsylvania). Mouse anti-AChR mAb A3-15 was kindly provided by Dr. Darwin K. Berg (UC San Diego). Mouse anti synaptic vesicle-associated glycoprotein (SV2) mAb 10h (Buckley and Kelly, 1985) was kindly provided by Dr. Steven S. Carlson (University of Washington). Cyanine 3.18 or cyanine 5.18 conjugated goat anti-ral and goat anti-mouse IgGs (hereafter abbreviated Cy3- or Cy5-GAR and Cy3- or Cy5-GAM) were purchased from Jackson Immunoresearch (West Grove, PA).

The percentage of neurons stained with each mAb was determined in double-label experiments in which all neurons were labeled with ethidium bromide. Ethidium bromide also stains non-neuronal cells, but these are many times smaller than neurons and readily distinguishable from them. Frozen sections were incubated in 10-30 nM anti-AChR $\mathrm{mAb}$ in PBS containing 5\% normal goat serum and $0.3 \%$ Triton X-100 (hereafter abbreviated SGT) for $1 \mathrm{hr}$, washed in PBS for $10 \mathrm{~min}$, incubated in 10-30 nM Cy5 conjugated secondary antibody and $12 \mathrm{nM}$ ethidium bromide in SGT for $1 \mathrm{hr}$, washed in PBS for $10 \mathrm{~min}$, and mounted in $4 \% n$-propyl gallate in $90 \%$ glycerol, $10 \%$ PBS to retard photobleaching (Giloh and Sedat, 1982). To control for mAb spccificity, we used mAbs made in the same species and having the same isotype that did not produce a signal in the nucleus. All large cells, assumed to be neurons on the basis of their size and the presence of neurites, were scored "by eye" as being either positive or negative for mAb staining. This approach was made possible by the high signal-to-noise ratio for staining in our experiments: neurons within the $\mathrm{SpL}$ were either well stained or unstained by any particular antibody. We verified the validity of this approach by performing a few experiments using image analysis to score neurons as positive or negative (see Results).

Double label experiments with rat and with mouse primary antibodies were done by incubating slide-mounted frozen sections with the following solutions (1) SGT for 10-20 min; (2) both primary mAbs, applied simultaneously at 10-30 nM, for 30-60 min; (3) PBS for $10 \mathrm{~min}$; (4) Cy3-GAR or GAM and Cy5-GAM or GAR in SGT for 30-60 min; and (5) PBS for $10 \mathrm{~min}$. Sections were mounted as before. Secondary antibodies were immunoadsorbed against the conspecific IgG to prevent cross-reactivity.

Double labeling with two primary antibodies from the same species (rat) was done with at least one primary $\mathrm{Ab}$ directly conjugated to a cyanine fluorochrome. Monoclonal antibodies 35 and 270 were reacted with cyanine 3.18 and cyanine 5.18 , respectively, according to instructions supplied by the vendor (Biological Detection Systems, Pittsburgh, PA), and were applied at 30-50 nM in SGT. The sequence of incubation steps was (1) SGT for 10-20 $\mathrm{min}$; (2) unconjugated primary rat $\mathrm{mAb}$ (c.g., 323) for $30 \mathrm{~min}$; (3) PBS for $10 \mathrm{~min}$; (4) Cy3- or Cy5-GAR for $30 \mathrm{~min}$; (5) PBS for $10 \mathrm{~min}$; (6) nonstaining $\mathrm{mAb}$, which should be bound by unoccupied antigen binding sites on the Cy3- or Cy5-labeled $\mathrm{GAR}$, thus preventing directly labeled rat $\mathrm{mAb}$ from subsequently binding there, for $30 \mathrm{~min}$; (7) PBS for $10 \mathrm{~min}$; (8) Cy3-mAb 35 or Cy5$\mathrm{mAb} 270$ for $30 \mathrm{~min}$; and (9) PBS for $10 \mathrm{~min}$. All incubations were done at room temperature.

The relationship between clusters of AChR-LI and synaptic sites was analyzed in $200 \mu \mathrm{m}$ vibratome sections of brains fixed by immersion in $1 \%$ formaldehyde in PBS. Sections were incubated in directly-labeled $30-50 \mathrm{nM} \mathrm{Cy3}-\mathrm{mAb} 35$ or Cy5-mAb 270 in PBS containing $5 \%$ normal goat serum overnight at $4^{\circ} \mathrm{C}$, washed three times for $15 \mathrm{~min}$ each in PBS at room temperature, and then incubated with anti-SV2 $\mathrm{mAb} 10 \mathrm{~h}$ in SGT for $6 \mathrm{hr}$ at $4^{\circ} \mathrm{C}$. Following three $15 \mathrm{~min}$ washes in PBS at room temperature, the sections were incubated overnight with 10-30 nM Cy3GAM or Cy5-GAM in SGT at $4^{\circ} \mathrm{C}$. After the three $15 \mathrm{~min}$ washes in PBS, the sections were mounted as before.

The specificity of most mAbs used in these experiments has been shown by immunoblotting. Blotting of gels show mAb A3-15 is specific for $\alpha 3$ (Vernallis et al., 1993); mAb 289 is specific for $\alpha 4$ (Whiting et al., 1987); mAb 35 is specific for $\alpha 5$ and $\alpha 1$ (Tzartos et al., 1981, Conroy et al., 1992); mAb 306, 318, and 319 are specific for $\alpha 7$ (Schoepfer et al., 1990, Conroy et al., 1992); mAb 305 is specific for $\alpha 8$ (Schoepfer et al., 1990); and mAb 270 is specific for $\beta 2$ (Whiting and Lindstrom, 1986a,b, Conroy et al., 1992). However, mAb 35 is not specific only for native AChRs containing the $\alpha 5$ subunit: it appears to recognize AChRs containing the $\alpha 3$ subunit (Haselbeck et al., 1994) and it recognizes an AChR of unknown subunit composition that also binds $\alpha-B g t$ (Pugh et al., 1995). However, the SpL is not immunoreactive for the $\alpha 3$ subunit (see Results), and the newly identified AChR (Pugh et al., 1995) is not detected in chicken brain. The anti- $\alpha 2 \mathrm{mAb}$ 323 was made against an $\alpha 2$ specific peptide sequence, but has not yet been shown to be specific for $\alpha 2$ in immunoblots (Lindstrom, Schoepfer, Whiting, and Gore, unpublished results).

We used a Bio-Rad MRC-600 laser scanning confocal imaging system with a krypton-argon ion laser having excitation lines at $568 \mathrm{~nm}$ and $647 \mathrm{~nm}$ to excite the cyanine fluorophores and collect images. The Cy 3 emission was collected between 578 and $618 \mathrm{~nm}$ (orange-red) and Cy5 emission was collected between 664 and $696 \mathrm{~nm}$ (far red, Sargent, 1994). Ethidium bromide emission was collected between 578 and 618 $\mathrm{nm}$ (orange-red). The laser was attenuated with a $3 \%$ transmission neutral density filter to reduce photobleaching. Images were collected with a Nikon $60 \times$ planapo oil objective with a numerical aperture of 1.4 and with the confocal detector aperture set at $3 \mathrm{~mm}$, yielding an optical section thickness of ca. $1.2 \mu \mathrm{m}$ in the orange-red to far-red (half-height). Most images were obtained by signal averaging and are printed without alteration of look up tables.

The percentage of AChR clusters at synaptic sites was determined by imaging boutons stained with anti-SV $2 \mathrm{mAb} 10 \mathrm{~h}$ and AChR clusters stained with Cy3-conjugated $\mathrm{mAb} 35$ in vibratome sections. AChR clus- 

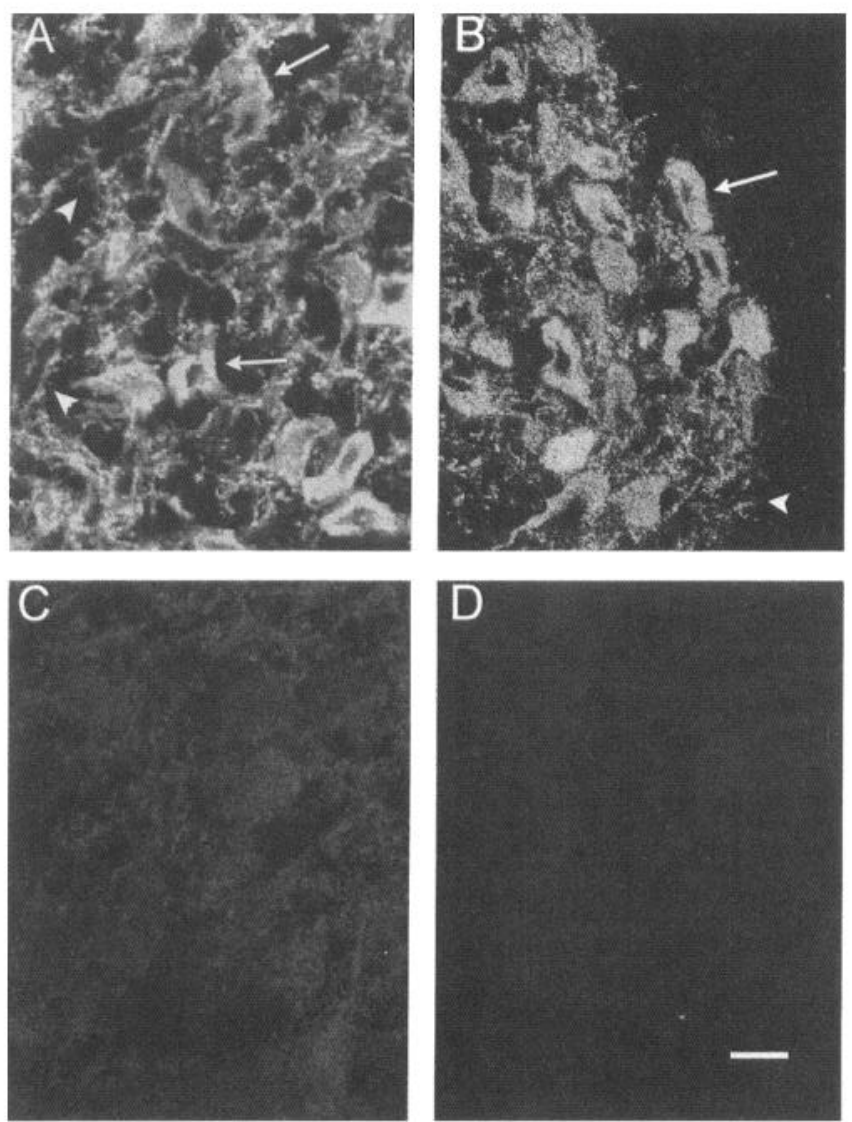

Figure 2. mAb 270 binds specifically to many neurons within the embryonic SpL. $A$ and $B$ show examples of SpL staining with $\mathrm{mAb}$ 270 ( $\beta 2$ ), while $C$ and $D$ show examples of staining with negative control mAb 319. Both mAbs are of the same subtype (IgGl), and were applied simultaneously. Note the clear difference in staining between $A$ and $C$, and $B$ and $D$. Arrows in $A$ and $B$ point to stained neuronal cell bodies, while arrowheads point to stained neuropil. Scale bar in $D, 20$ $\mu \mathrm{m}$.

ters and synaptic boutons were identified with an image analysis program (OPTIMAS) by setting thresholds so that the program marked all objects previously considered by eye to represent AChR clusters or boutons. The degree of overlap between AChR clusters and boutons was determined using a digitizing pad.

\section{Results}

Detection of AChR subunit immunoreactivity in chick SpL

An example of specific neuronal AChR subunit immunoreactivity is seen in Figure 2, $A$ and $B$, with mAb 270. Both cell bodies (arrows) and neuropil (arrowheads) are stained in this example. The stained cell bodies presumably belong to neurons, given their size (diameter: 20-40 $\mu \mathrm{m}$ ) and morphology. A control $\mathrm{mAb}$ (Fig. 2C,D) of the same subtype as mAb 270 (IgG1) and used in the same experiment on different sections did not produce a detectable signal, indicating that nonspecific association of either primary or secondary IgGs with chick tissue cannot account for the signal.

The fraction of neurons labeled with each mAb was assessed in double label experiments by dividing the number of mAbstained neurons by the total number of neurons, determined using ethidium bromide, which stains neurons quantitatively (Table 1). The percentage of neurons immunoreactive for each subunit varied from $90 \%(\alpha 5 / \beta 2)$ to less than $15 \%(\alpha 8$, Table 1$)$. The

\begin{tabular}{lllll}
\hline $\begin{array}{l}\text { Table 1. } \\
\text { subunits }\end{array}$ & Percentages of SpL neurons immunoreactive for AChR \\
& \multicolumn{5}{l}{} \\
mAb & $\begin{array}{l}\text { Speci- } \\
\text { ficity }\end{array}$ & Embryonic & Adult & $p$ \\
\hline 35 & $\alpha 5$ & $93 \pm 6 \%$ & $89 \pm 17 \%$ & 0.8 \\
270 & $\beta 2$ & $90 \pm 5 \%$ & $90 \pm 12 \%$ & 0.8 \\
323 & $\alpha 2$ & $72 \pm 13 \%$ & $59 \pm 38 \%$ & 0.9 \\
306 & $\alpha 7$ & $21 \pm 14 \%$ & $27 \pm 14 \%$ & 0.6 \\
305 & $\alpha 8$ & $13 \pm 12 \%$ & $11 \pm 19 \%$ & 0.9 \\
289 & $\alpha 4$ & $0 \%$ & $18 \pm 12 \%$ & 0.009 \\
A3-15 & $\alpha 3$ & $0 \%$ & $0 \%$ & N.A.
\end{tabular}

Data show the percentage of neurons containing each AChR subunit-LI for both embryonic and adult SpL. Embryonic data were taken from embryos at 20-21 d of development. Adult data were taken from 14 week hens. Values represent the mean and SD taken from 5-8 fields of neurons. The number of neurons analyzed for each sample ranged from 60 to 100. None of the adult means were significantly different from the embryonic means for the same $\mathrm{mAb}$, except mAb 289.

fact that the immunoglobulins (IgGs) mAb $323(\alpha 2)$, mAb 306 $(\alpha 7)$, and mAb $305(\alpha 8)$ did not stain all the neurons in the SpL is unlikely to be due to incomplete penetration of the antibodies into the $20 \mu \mathrm{m}$ thick sections during the 30-60 min incubation periods, since the IgGs mAbs 35 and 270 presumably did completely penetrate the sections, inasmuch as they stained nearly all neurons in the nucleus. Another possible explanation for our finding that only some neurons are stained with mAbs $323(\alpha 2)$, $306(\alpha 7)$, and $305(\alpha 8)$ is that these antibodies stain neurons only weakly, such that some cells fall below our threshold for immunoreactivity, which is determined by eye. This possibility would be evident if the frequency distribution of gray values (pixel intensities) for neurons stained with these mAbs overlapped with that for neurons stained with a control $\mathrm{mAb}$. Figure 3 shows that this is not the case for mAb 323 (similar results were obtained with mAbs 306 and 305). The frequency distribution of neurons stained with mAb 323 is bimodal and contains two populations of gray values: a large population that does not overlap with gray values measured in a control incubation and a smaller population that overlaps almost completely with control gray values (Fig. 3). This result confirms the validity of classifying cells as immunopositive or immunonegative "by eye," especially since the fraction of neurons that stain with mAb 323 is nearly identical when assessed quantitatively and by eye. Thus, the mAb 323-negative neurons are not simply the most lightly stained of a unimodal population but represent a distinct class of cells with no detectable immunoreactivity. The widely varying percentages of neurons immunoreactive for each of several AChR subunits suggests the existence of diverse cell types in the SpL nucleus. We have confirmed this by simultaneously staining tissue for immunoreactivity using pairs of subunit-specific mAbs.

\section{Neuron classes in the SpL}

Many neurons within the $\mathrm{SpL}$ are stained with either mAb 35 $(\alpha 5)$ or mAb $270(\beta 2)$ (Table 1), and we therefore expected many neurons to contain both $\alpha 5-\mathrm{LI}$ and $\beta 2$-LI in double label experiments. Indeed, a majority of neurons in the nucleus are immunoreactive for both mAb 35 ( $\alpha 5$, Fig. $4 A$, left panel) and mAb 270 ( $\beta 2$, Fig. $4 A$, right panel). Double staining of a majority of SpL neurons with both mAb $35(\alpha 5)$ and mAb 270 ( $\beta 2$ ) could be artifactual. One potential problem is that light 


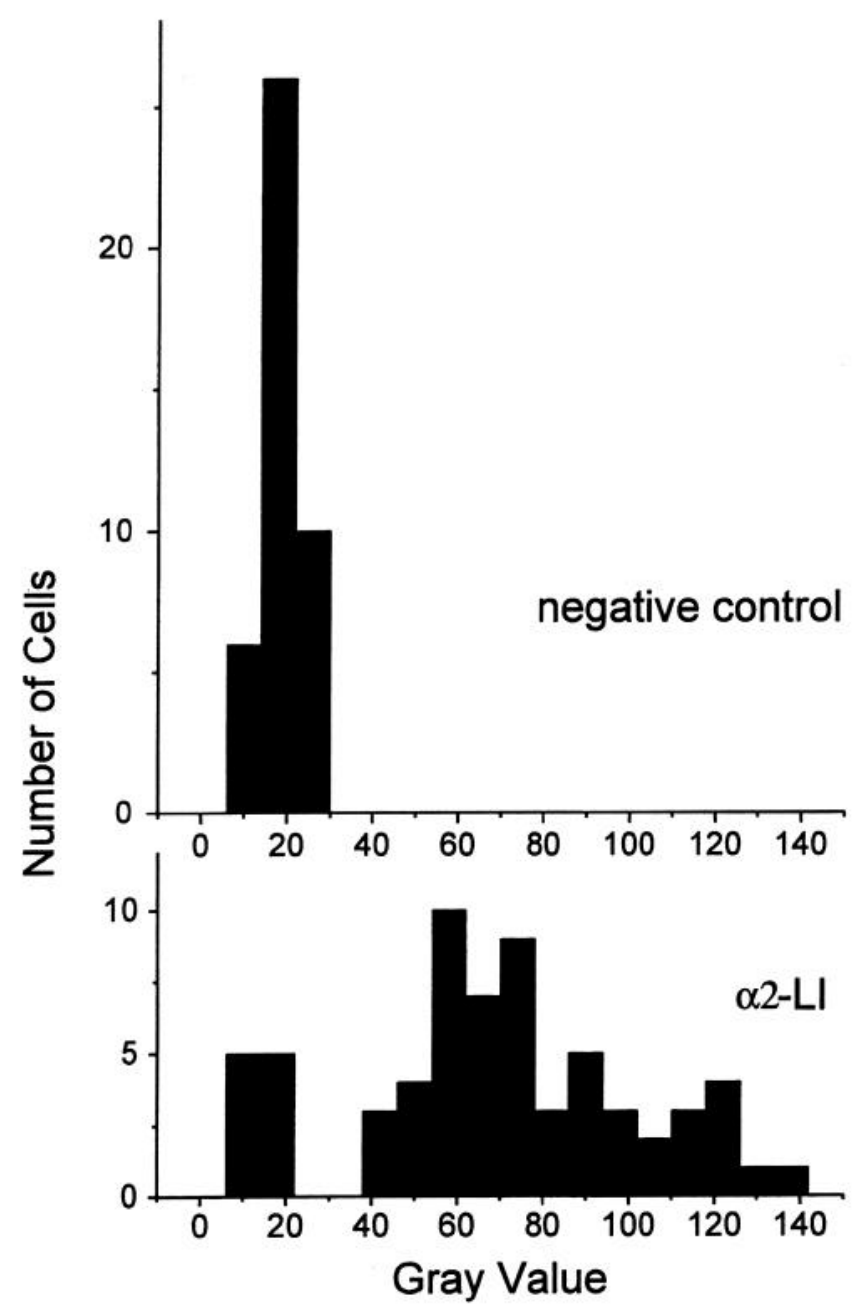

Figure 3. The frequency distribution of neurons stained with anti- $\alpha 2$ $\mathrm{mAb} 323$ is bimodal and contains two populations of gray values: a large population that does not overlap with gray values measured in a control incubation and a smaller population that overlaps completely with control gray values.

emitted by one fluorophore may be collected by the channel designed for the other fluorophore (spectral crossover). Except under extreme conditions, Cy5 will not emit detectably in the Cy3 channel (578-618 nm). However, Cy3 does emit slightly in the Cy5 channel (664-696 nm), but as illustrated in Figure 4, B and $C$, the extent of crossover is insignificant. A second source of artifact that could explain why nearly all SpL neurons stain for both mAb $35(\alpha 5)$ and mAb $270(\beta 2)$ arises because both mAbs were made in a common species (rat). We have eliminated the obvious problem of indirectly visualizing the binding of each $\mathrm{mAb}$ by labeling one of them directly with fluorochrome. Our experiments are typically done by incubating the tissue first with the unconjugated primary $\mathrm{mAb}$ (e.g., 35), then with a conjugated secondary $\mathrm{Ab}$, and finally with the directly labeled primary $\mathrm{mAb}$ (e.g., 270). It is still possible, however, that the mAb colocalization results because the directly conjugated $\mathrm{mAb}$ is recognized by the bound secondary $\mathrm{Ab}$, one of whose antigen binding sites is free. To eliminate this possibility we have preceded the final step with an additional one, in which the tissue is incubated with an unconjugated rat mAb (see Materials and Methods). The colocalization of $\alpha 5-\mathrm{LI}$ and $\beta 2$-LI is thus unlikely to be an artifact; moreover, we note that other experiments utilizing two mAbs
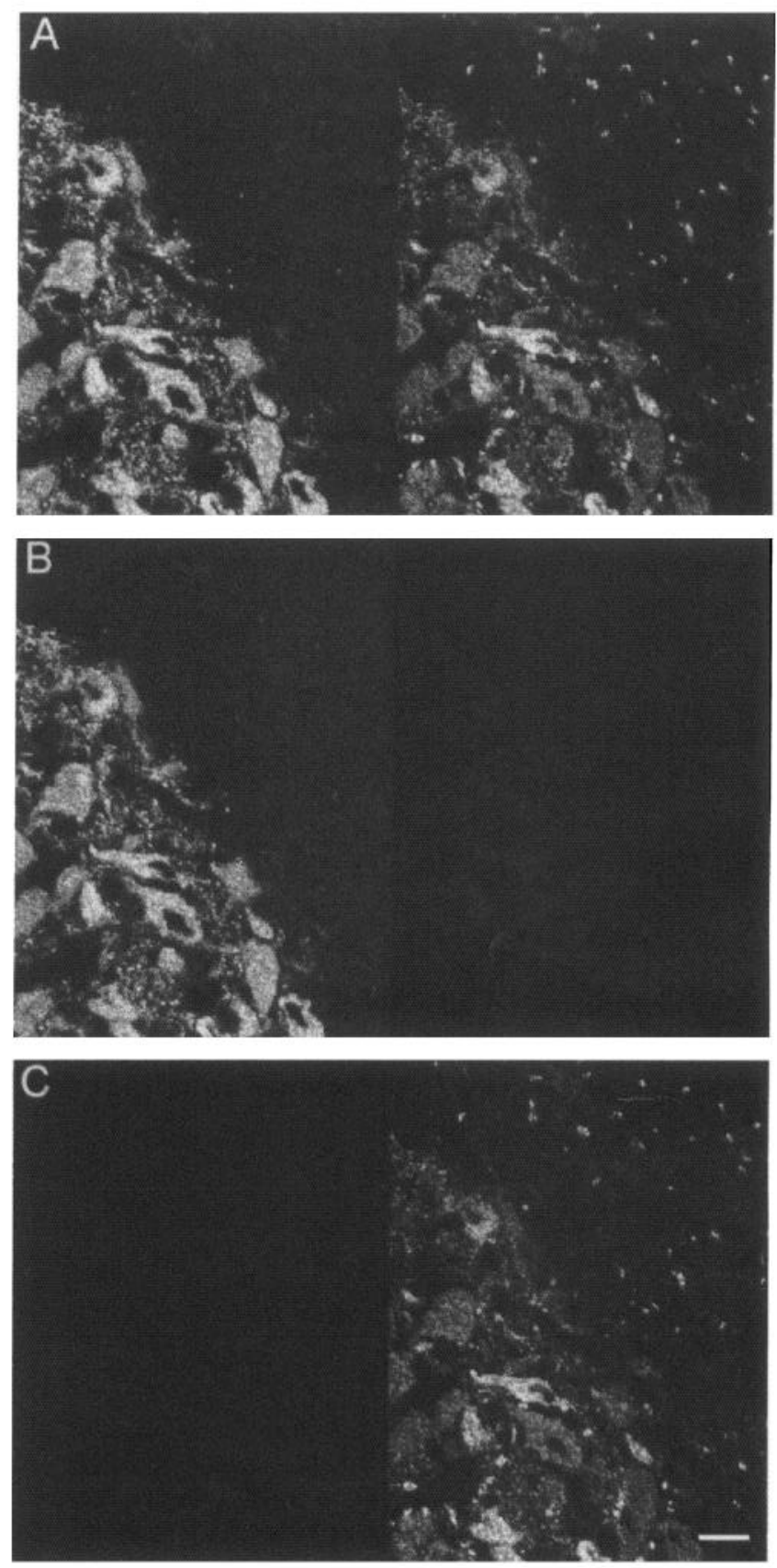

Figure 4. Dual staining of $\mathrm{SpL}$ neurons with both $\mathrm{mAb} 35(\mathrm{Cy} 3)$ and mAb 270 (Cy5) cannot be explained by spectral crossover between Cy3 and Cy5 fluorochromes. A shows images from a field of $\mathrm{SpL}$ neurons stained with both mAb 35 (Cy3) and mAb 270 (Cy5) excited with both the $568 \mathrm{~nm}$ excitation line and the $647 \mathrm{~nm}$ excitation line. The signal in the left channel (orange-red) arises principally from Cy3, since it is present when only the $568 \mathrm{~nm}$ line is used $(B)$ and absent when only the $647 \mathrm{~nm}$ line is used $(C)$. Likewise, the signal in the right channel (far-red) arises principally from Cy5, since it is present when only the $647 \mathrm{~nm}$ line is used $(C)$ and absent when only the $568 \mathrm{~nm}$ line is used (B). Scale bar, $20 \mu \mathrm{m}$.

from the same species do not result in complete colocalization (see below). Thus, our results are best explained by assuming that nearly all neurons are immunoreactive for both $\alpha 5$ and $\beta 2$ AChR subunits.

Approximately $70 \%$ of the neurons in the SpL contained $\alpha 2$ LI (Table 1). Figure $5 C$ illustrates the type of staining seen in 

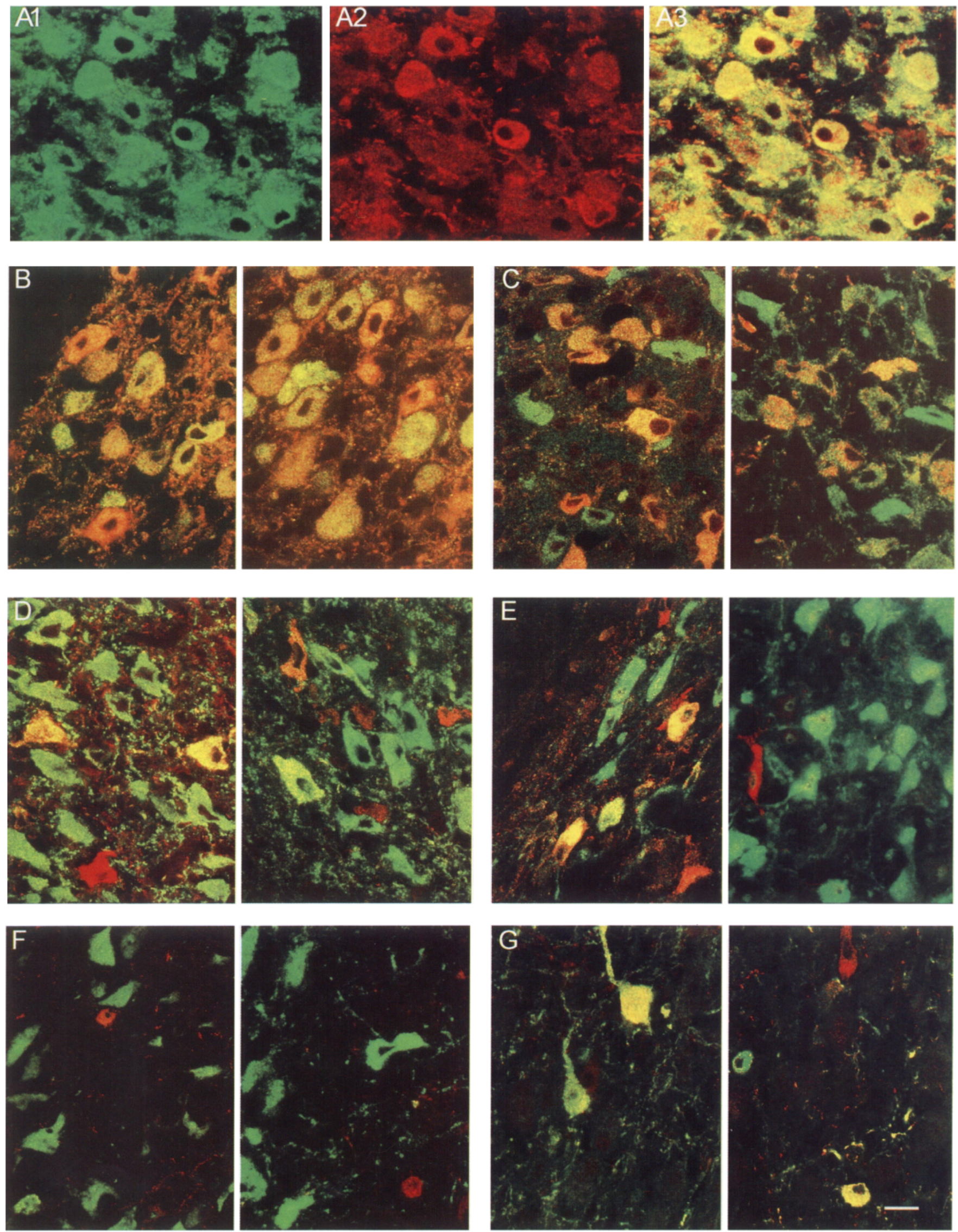

Figure 5. Double labeling reveals multiple classes of neurons in the SpL, based on their expression of AChR subunit-LI. A shows a field of SpL neurons stained with both mAb 35 ( $A 1$, Cy3 channel, rendered green) and with mAb $270(A 2, \mathrm{Cy} 5$ channel, rendered red), and a color merge of 


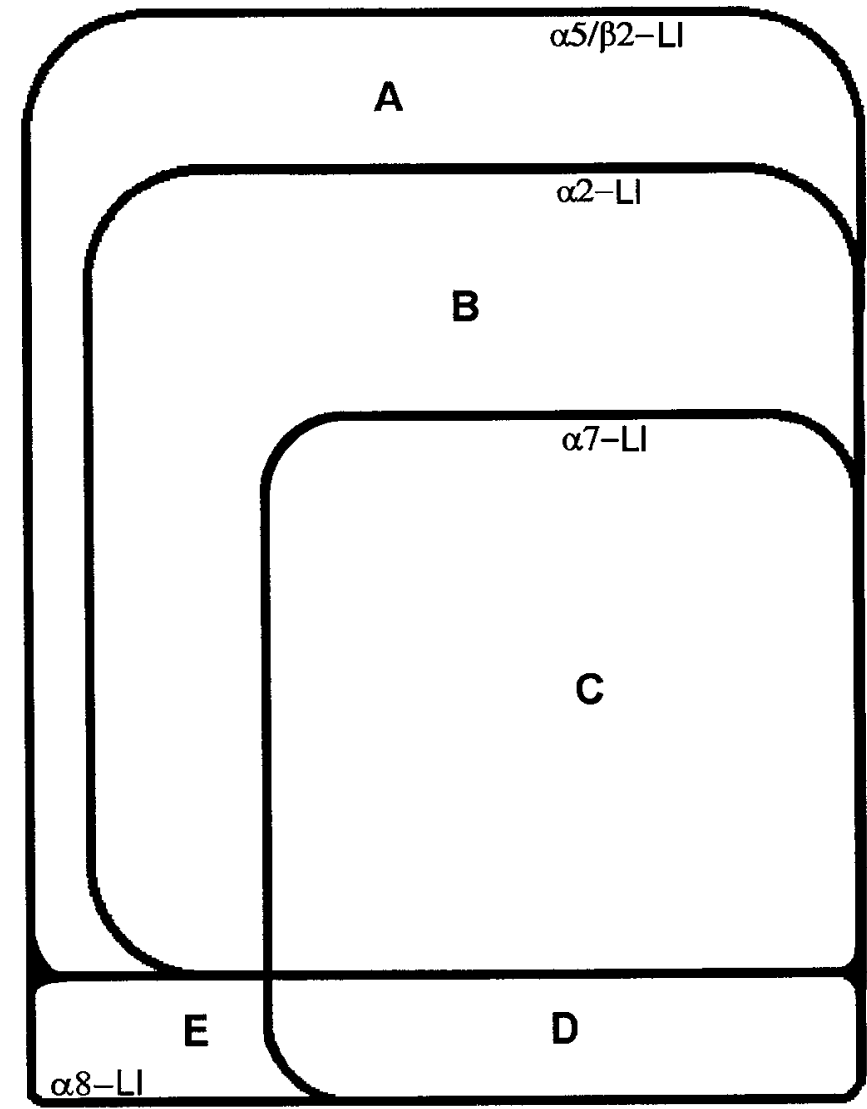

Figure 6. The Venn diagram illustrates the neuronal classes in the $\mathrm{SpL}$, based on the presence of AChR-LI. The outer rectangle represents all neurons in the $\mathrm{SpL}$, while the set sizes are proportional to the fraction of cells containing each subunit-LI. Note that the majority of neurons contain both $\alpha 5$ - and $\beta 2$-LI. Cells expressing other subunit-LIs bear distinct relationships with this set of neurons: cells containing $\alpha 2-\mathrm{LI}$ arc a subset of $\alpha 5 / \beta 2$-positive neurons, cells containing $\alpha 7$-LI comprise a set that intersects with $\alpha 5 / \beta 2$-positive neurons, and cells containing $\alpha 8$-LI comprise a set that does not intersect with $\alpha 5 / \beta 2$-positive neurons. The Venn diagram illustrates that at least five classes of neurons exist within the $\mathrm{SpL}$ (classes $A-E$ ).

the SpL after double labeling with $\mathrm{mAb} 323$, which recognizes $\alpha 2$ (Fig. $5 C$, red color), and $m A b 35$, which recognizes $\alpha 5$ (Fig. $5 C$, green color). Note that neurons containing both subunit-LIs (yellow neurons in Fig. $5 C$ ) are prevalent. Neurons containing only $\alpha 5$-LI are also present (Fig. $5 C$, green neurons); however, there are no neurons containing only $\alpha 2$-LI (Fig. $5 C$, red). Similar results were obtained in double label experiments using $\mathrm{mAb}$ $323(\alpha 2)$ and mAb 270 ( $\beta 2$, not shown). Consequently, $\alpha 2-\mathrm{LI}$ is present in a subset of the neurons that also contain $\alpha 5-\mathrm{LI} / \beta 2$ LI. Note that our interpretation would require modification if
mAb 35 were not specific for $\alpha 5$ in these experiments. If, for example, mAb 35 recognized either $\alpha 5$ or $\alpha 2$, then neurons having $\alpha 2-\mathrm{LI}$ and not $\alpha 5$-LI (which would be mAb 35 positive and mAb 323 positive) would be misinterpreted as having both $\alpha 2-$ $\mathrm{LI}$ and $\alpha 5$-LI. We can argue against the possibility that mAb 35 recognizes a set of SpL neurons having $\alpha 2-\mathrm{LI}$ and not $\alpha 5-\mathrm{LI}$, since we find that mAb 35 recognizes precisely the same set of neurons recognized by mAb 268 (not shown), which recognizes an epitope on the $\alpha 5$ subunit distinct from that recognized by mAb 35 (Whiting ct al., 1987; Conroy ct al., 1992). It is very unlikely that both mAbs 35 and 268 crossreact with $\alpha 2$ subunits, given their different epitope specificities. These results suggest that there are two classes of $\alpha 5 / \beta 2$-immunoreactive cells: those that contain $\alpha 2-$ LI and those that do not. Approximately $20 \%$ of the SpL neurons were stained with mAb $306(\alpha 7$, Table 1). Double label experiments with mAb $35(\alpha 5)$ and mAb $306(\alpha 7)$ show neurons that contain $\alpha 5-\mathrm{LI}$ alone (Fig. $5 D$, green neurons), neurons that contain $\alpha 7$-LI alone (Fig. $5 D$, red neurons), and neurons that contain both (Fig. $5 D$, yellow neurons). Similarly, double label experiments with mAb $323(\alpha 2)$ and mAb $306(\alpha 7)$ show neurons that contain $\alpha 2-\mathrm{LI}$ alone (Fig. $5 E$, green neurons), neurons that contain $\alpha 7$-LI alone (Fig. $5 E$, red neurons), and neurons that contain both (Fig. $5 E$, yellow neurons). Thus, $\alpha 7-$ LI is present in at least two populations of neurons: (1) those that lack $\alpha 5$-LI (and therefore lack $\alpha 2-\mathrm{LI}$ ), and (2) those that contain $\alpha 2$-LI (and therefore contain $\beta 2 / \alpha 5-\mathrm{LI}$ ).

Fewer than $15 \%$ of neurons in the SpL contained $\alpha 8$-LI (Table 1). Double label experiments with mAb $35(\alpha 5)$ and $\mathrm{mAb} 305$ $(\alpha 8)$ revealed neurons that contain $\alpha 5$-LI only, neurons that contain $\alpha 8$-LI only, but no neurons containing both $\alpha 5$ and $\alpha 8$-LI (Fig. $5 F$ ). Double label experiments with $\mathrm{mAb} 306(\alpha 7)$ and mAb $305(\alpha 8)$ showed neurons that contain $\alpha 7-\mathrm{LI}$, neurons that contain $\alpha 8$-LI, and neurons that contain both $\alpha 7$ and $\alpha 8$-LIs (Fig. 5G). This experiment helps to define at least three classes of neurons having $\alpha 7$-LI. Previously, we showed that some $\alpha 7$ positive neurons contained $\alpha 2-\mathrm{LI}$, while others did not. Of those that did not, we can now say that some are immunoreactive for $\alpha 8$, while others are not. Thus, among the neurons containing $\alpha 7-\mathrm{LI}$, there are those that contain $\alpha 2-, \alpha 5-$, and $\beta 2-\mathrm{LI}$; those that contain $\alpha 8$-LI but not $\alpha 2-, \alpha 5-$, or $\beta 2-\mathrm{LI}$; and those that lack $\alpha 8-, \alpha 2-, \alpha 5-$, and $\beta 2-$ LI. Neurons containing $\alpha 8-$ LI in double labcl expcriments show two different patterns: neurons containing $\alpha 8$-LI only and neurons containing $\alpha 7-$ and $\alpha 8$-LI. None of the neurons in the embryonic SpL stained for mAb $289(\alpha 4)$, although this $\mathrm{mAb}$ did stain neurons in other nuclei and $\mathrm{SpL}$ neurons at later stages of development (see below).

We found no neurons within the SpL that were immunoreactive for anti- $\alpha 3 \mathrm{mAb} A 3-15$, although this mAb did stain virtually all neurons in the chicken ciliary ganglion.

These data demonstrate that several classes of neurons exist

$\leftarrow$

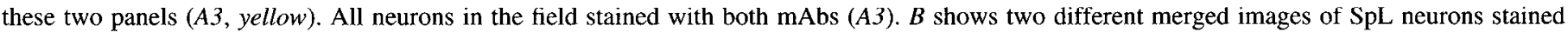

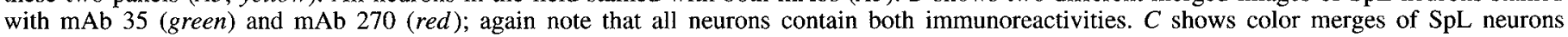

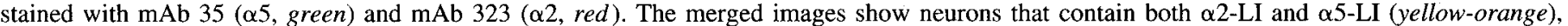

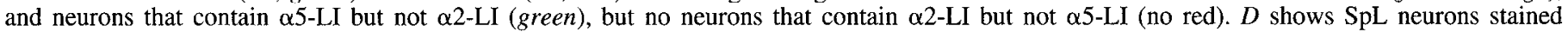

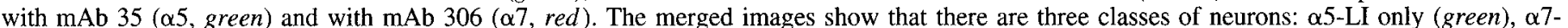

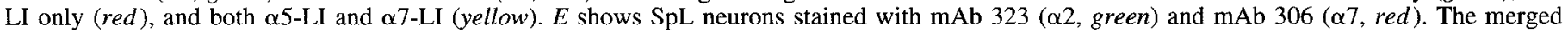

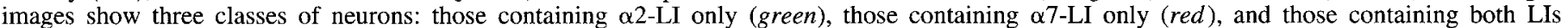

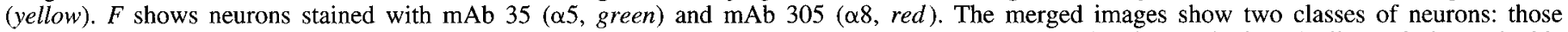

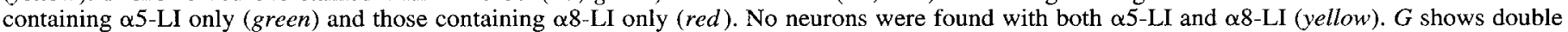

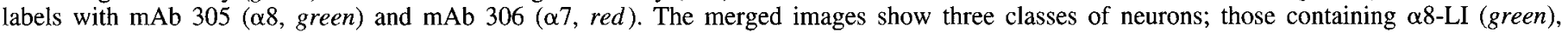
neurons containing $\alpha 7$-LI (red), and neurons containing both LIs (yellow). Scale bar in $G, 20 \mu \mathrm{m}$. 
within the SpL, based on the presence of AChR-LI. The Venn diagram shown in Figure 6 illustrates the neuronal classes and their relation to each other. The outer rectangle represents all neurons in the $\mathrm{SpL}$, while the set sizes are proportional to the fraction of cells containing each subunit-LI. Since $\alpha 5 / \beta 2$-positive neurons and $\alpha 8$-positive neurons are non-intersecting sets, and since together these sets account for all neurons (Table 1), we suspect that all neurons in the $\mathrm{SpL}$ are immunoreactive for at least one AChR subunit. Note that the majority of neurons contain both $\alpha 5$ - and $\beta 2$-LI. Neurons expressing other subunitLIs bear distinct relationships with this set of neurons: neurons containing $\alpha 2$-LI are a subset of $\alpha 5 / \beta 2$-positive neurons, neurons containing $\alpha 7$-LI comprise a set that intersects with $\alpha 5 / \beta 2$ positive (and $\alpha 2$-positive) neurons, and neurons containing $\alpha 8$ LI comprise a set that does not intersect with $\alpha 5 / \beta 2$-positive neurons. The existence of at least five unique classes of neurons (Fig. 6, classes A-E) is demonstrated by the results of double label experiments illustrated in Figure 5. For example, double label experiments with mAbs $323(\alpha 2)$ and $306(\alpha 7)$ reveal that some neurons have $\alpha 2$-LI, but not $\alpha 7$-LI. Since these neurons contain $\alpha 2$-LI, they must also have $\alpha 5$-LI and $\beta 2-\mathrm{LI}$, because neurons with $\alpha 2$-LI are a subset of the neurons with $\alpha 5 / \beta 2-\mathrm{LI}$. Analogously, since these neurons contain $\alpha 5 / \beta 2-\mathrm{LI}$, they cannot also contain $\alpha 8$-LI, because neurons having $\alpha 5 / \beta 2$-LI do not overlap with the neurons having $\alpha 8$-LI. These neurons are therefore placed in category B $(\alpha 2+, \alpha 5+, \alpha 7-, \alpha 8-, \beta 2+)$. Four of the five cell classes illustrated in the Venn diagram are evident from directly analyzing the outcome of the double label experiments as we have just detailed for category B. However, the cells in category $\mathrm{A}(\alpha 2-, \alpha 5+, \alpha 7-, \alpha 8-, \beta 2+)$ are assumed to exist by inference. Neurons that are $\alpha 2$-negative and $\alpha 5 / \beta 2$ positive must be $\alpha 8$-negative, but we don't know if they are also $\alpha 7$-negative (this could be established with triple label experiments). Nonetheless, we can argue that at least some of these neurons are $\alpha 7$-negative by examining the percentage of cells immunoreactive for each subunit (Table 1); about $20 \%$ of neurons in the SpL are positive for $\alpha 5 / \beta 2$ and negative for $\alpha 2$ (the $90 \% \alpha 5 / \beta 2$-positive minus the $70 \% \alpha 2$-positive), and an equal proportion are positive for $\alpha 7$. Double label experiments show that a portion of these $\alpha 7$-positive neurons are both $\alpha 5 / \beta 2$-negative and $\alpha 2$-negative, and another portion are both $\alpha 5 / \beta 2$-positive and $\alpha 2$-positive. This does not leave enough $\alpha 7$-positive neurons available to fill the $20 \%$ gap left by the $\alpha 5 / \beta 2$-positive, $\alpha 2$-negative neurons. Therefore, at least some of these $\alpha 5 / \beta 2$ positive, $\alpha 2$-negative neurons must also be $\alpha 7$-negative (category A). It is possible that other $\alpha 5 / \beta 2$-positive, $\alpha 2$-negative neurons are $\alpha 7$-positive; if so, these neurons represent a sixth class: one not illustrated in the Venn diagram $(\alpha 2-, \alpha 5+, \alpha 7+$, $\alpha 8-, \beta 2+$ ). Clearly, more experiments are needed to complete the remainder of the Venn diagram. However, it is at least as important to understand the basis and the consequences of this diversity as to document all of its details.

We repeated these immunofluorescence experiments on 1214 week chickens to determine if the degree of diversity in embryonic expression of AChR-LIs is sustained. The percentages of cells containing $\alpha 2-\mathrm{LI}, \alpha 5-\mathrm{LI}, \alpha 7-\mathrm{LI}, \alpha 8-\mathrm{LI}$, and $\beta 2$-LI did not change significantly in the $12-14$ week SpL (Table $1 ; 0.6<$ $P<0.9$ ). Several cell classes present in embryonic chicks (Fig. $6)$ are present as well. For instance, $\alpha 2-\mathrm{LI}$ is still present in a subset of the cells containing $\alpha 5$-LI (not shown). However, an additional AChR-LI, $\alpha 4-\mathrm{LI}$, is present in the 14 week old SpL, but absent in the embryonic SpL (Fig. 7). We calculate that $18 \%$
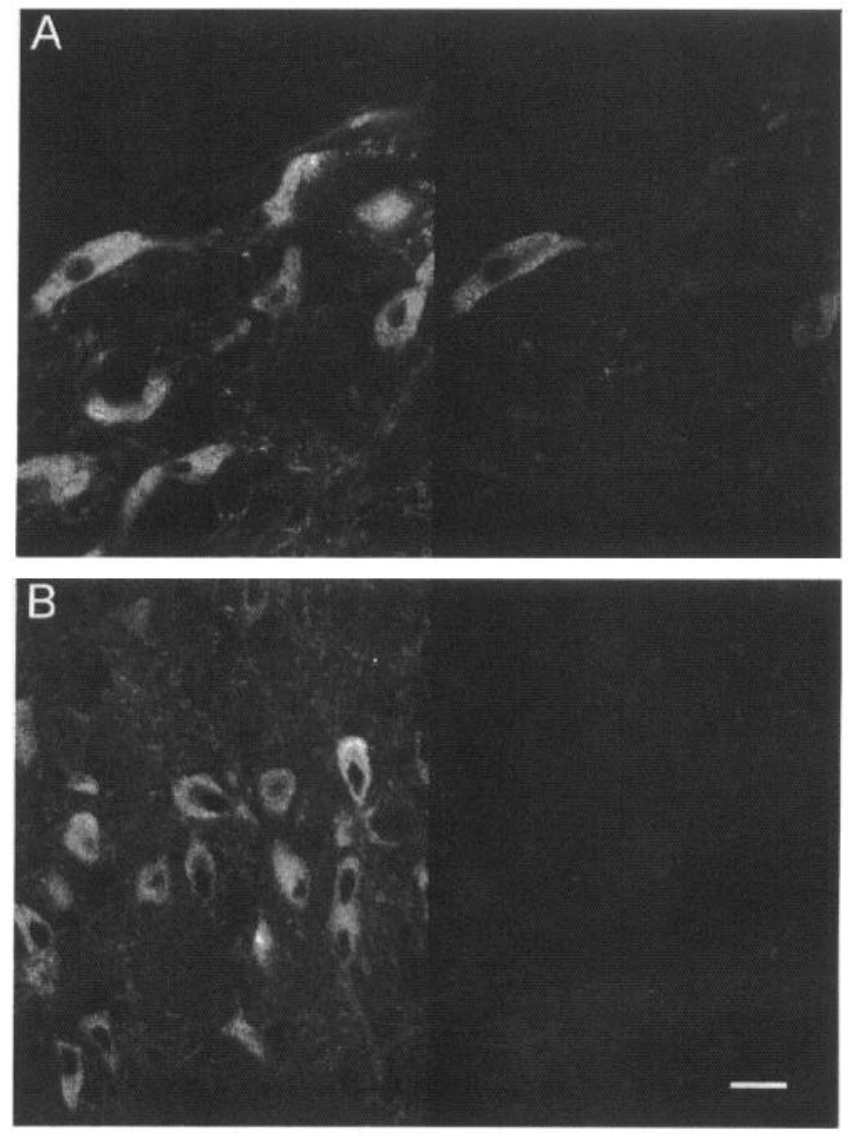

Figure 7. Neurons in adult, but not embryonic SpL, have $\alpha 4-$ LI. A shows a field of 14 week SpL neurons double labeled with mAb 35 $(\alpha 5, \mathrm{Cy} 3$, left panel) and mAb 289 ( $\alpha 4$, Cy5, right panel). B shows a field of embryonic SpL neurons similarly stained. Note that $\alpha 4-\mathrm{LI}$ is only present in a subset of adult $\mathrm{SpL}$ neurons $(A$, right panel $)$ and that all neurons containing $\alpha 4-\mathrm{LI}$ also contain $\alpha 5-\mathrm{LI}(A$, left and right panels). Scale bar in $B, 20 \mu \mathrm{m}$.

of all neurons in the SpL contain $\alpha 4$-LI (Table 1). All cells containing $\alpha 4$-LI also contain $\alpha 5$ - and $\beta 2$-LI in the 14 week old SpL (Fig. 7A). Therefore, neurons containing $\alpha 4$-LI are a subset of the neurons containing $\alpha 5 / \beta 2$-LI.

\section{Detection of AChR subunit immunoreactivity in the chick optic tectum}

The SpL neurons project to a layer of the optic tectum called the stratum griseum centrale (SGC, Reiner et al., 1982). Swanson et al. (1983) showed that the SGC of posthatch 2 d chicks contains $\alpha 5-\mathrm{LI}$, and since this immunoreactivity declines after ipsilateral SpL lesioning, they suggested that SpL neurons transport AChRs to the SGC (Swanson et al., 1983). To identify candidate AChR subunits in addition to $\alpha 5$ that might be transported to the optic tectum from the $\mathrm{SpL}$, we examined the optic tectum for immunoreactivity corresponding to other AChR subunits found in the SpL. Britto et al. (1992a) found mAb $270 \beta 2$ $\mathrm{LI}$ in the SGC, and we here report similar results (Fig. 8). The staining is characterized by bright, neuropil-like immunoreactivity with few stained neuronal cell bodies (Fig. 8A). The stained neuropil is presumed to represent the SGC of the optic tectum, based on the description of cellular lamination according to Kuenzal and Mason (1988). The optic tectum also stained both with $\mathrm{mAb} 306(\alpha 7)$ and mAb $305(\alpha 8$, Fig. $8 B, C)$. However, 

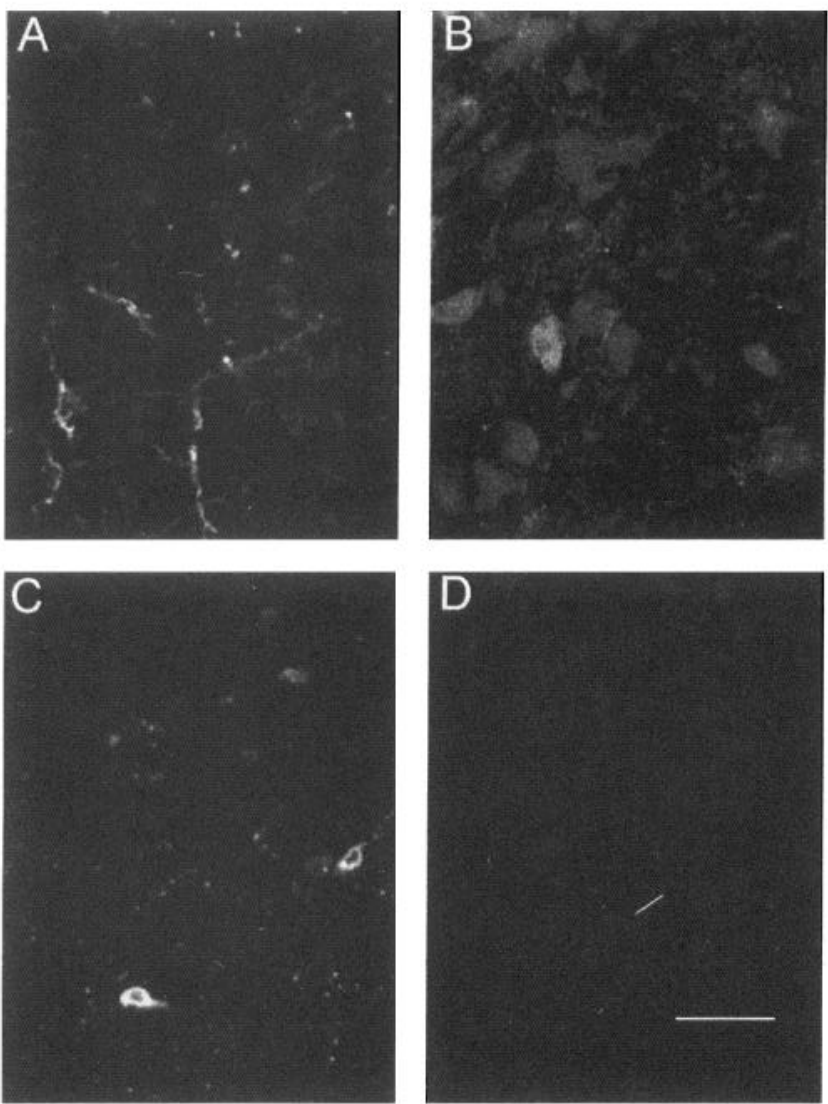

Figure 8. The SGC layer of the embryonic optic tectum is immunoreactive for AChR subunits. $A$ shows mAb $270(\beta 2)$ staining in the SGC. Note the neuropil-like staining, with no cell bodies visible in the field. $B$ shows SGC staining with mAb $306(\alpha 7)$. Both punctate neuropil-like staining and cell body staining are evident. $C$ shows an examples of mAb $305(\alpha 8)$ staining to SGC. There is both cell body and punctate, neuropil-like staining. In contrast, $D$ shows that mAb $323(\alpha 2)$ does not stain the SGC. Scale bar, $50 \mu \mathrm{m}$.

unlike mAb 270, both mAb 306 and mAb 305 also stained cell bodies within or near the SGC. Figure $8 B$ shows an example produced with anti- $\alpha 7 \mathrm{mAb} 306$; there is both punctate neuropil staining and light immunoreactivity present in many neuronal cell bodies, which lacked extensive stained processes. Figure $8 C$ ( $\alpha 8$-LI) also shows punctate neuropil staining; here, however, neuronal cell bodies are intensely stained and have short immunoreactive processes. In contrast, the optic tectum SGC showed no immunoreactivity for mAbs $323(\alpha 2$, Fig. $8 D)$ or 35 ( $\alpha 5$, not shown). Thus, the SGC of the late embryonic optic tectum is immunoreactive for $\beta 2$ (mAb 270), $\alpha 8$ (mAb 305), and $\alpha 7$ (mAb 306) but not for $\alpha 5$ (mAb 35), $\alpha 2$ (mAb 323), or $\alpha 4$ (mAb 289) AChR subunits.

We repeated the staining of the SGC in 14 week old chickens to determine whether novel AChR-LIs appear after hatching. Overall, the 14 week SGC resembles the late embryonic SGC in containing $\beta 2$-LI (Fig. 9C,D) and $\alpha 7$ - and $\alpha 8$-LI (not shown), while lacking $\alpha 2$ - and $\alpha 4$-LI (not shown). The 14 week optic tectum differs from its embryonic counterpart in displaying $\alpha 5$ LI (Fig. 9A,B). Swanson et al. (1983) showed that $\alpha 5$-LI is present in $2 \mathrm{~d}$ posthatch chickens, and we find that its expression is sustained during the subsequent several months.
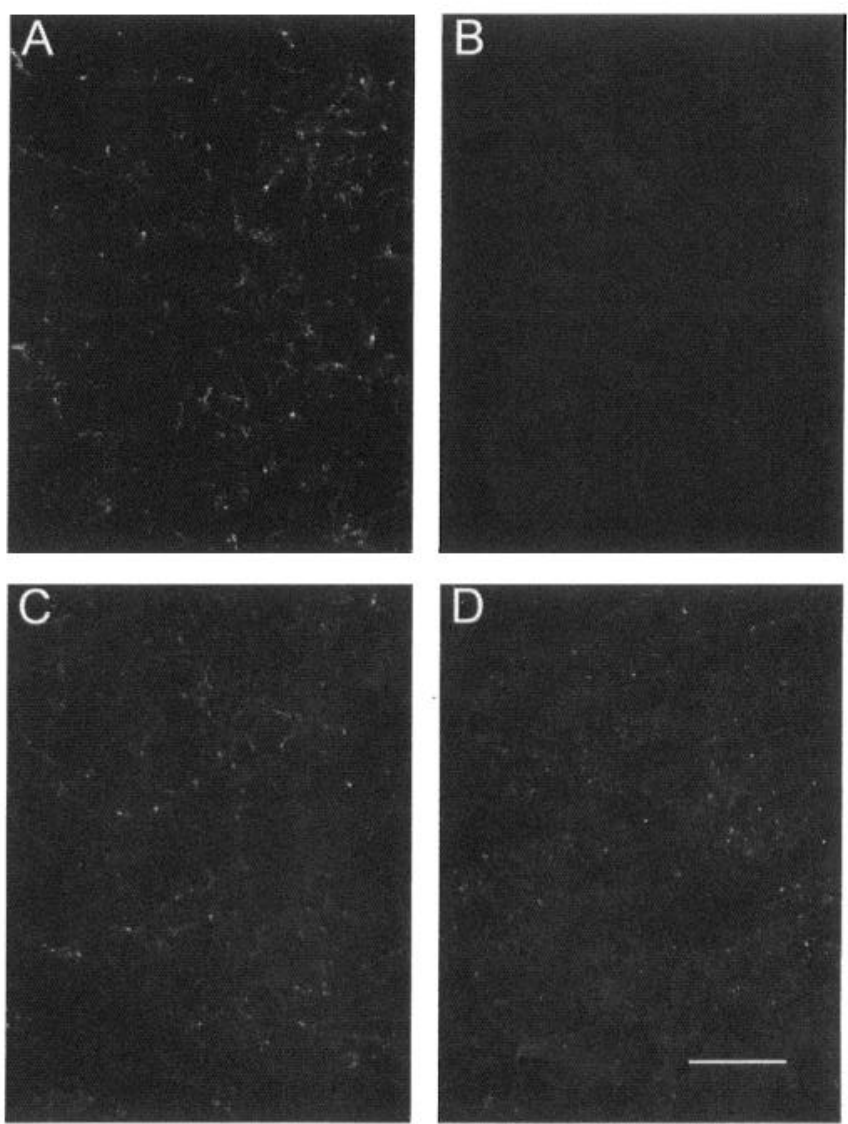

Figure 9. The adult optic tectum, but not the embryonic optic tectum, contains $\alpha 5$-LI. A shows punctate $\alpha 5$-LI in the SGC of the adult optic tectum. However, $B$ shows that $\alpha 5$-LI is not present in the embryonic SGC layer of the optic tectum. $C$ and $D$ show that $\beta 2$-LI is present in the adult $(C)$ and embryonic $(D)$ optic tectum SGC. Scale bar, $50 \mu \mathrm{m}$.

\section{Synaptic localization of AChRs}

The occurrence of AChR clusters at synaptic sites was assessed in vibratome sections of the $\mathrm{SpL}$ of both late embryonic and 14 week animals. Figure 10Al shows an optical section of an embryonic neuron stained for mAb 35 ( $\alpha 5$, green), while Figure $10 A 2$ shows the same neuron stained for synaptic sites (SV2, red). Figure $10 A 3$ shows a color merge of Figure 10, Al and $A 2$, and illustrates that some clusters of AChR-LI are synaptic. However, Figure $10 B-D$ shows that many AChR clusters are extrasynaptic. In Figure $10 \mathrm{D}$ examples of both synaptic and extrasynaptic clusters of AChR-LI are indicated by arrows and arrowheads, respectively. Many AChR clusters do not appear simply to be slightly displaced from synaptic sites, but exist in isolation from detectable SV2-LI. We calculated, using image analysis software, that only $25 \pm 20 \%$ of the AChR clusters are located at synaptic sites in the embryonic SpL ( $n=20$ neurons). The 14 week old $\mathrm{SpL}$ also has a preponderance of extrasynaptic AChR clusters (Fig. $10 E-G$ ). At this age only $11 \pm 10 \%$ of the AChR clusters are located at synaptic sites as determined by SV2 staining ( $n=20$ neurons, significantly different from embryonic mean, $p=0.009$ ).

\section{Discussion}

Despite the wide distribution of AChR subunit mRNAs in the CNS (e.g., Wada et al., 1989), there are few central synapses where AChRs are thought to mediate fast synaptic transmission 

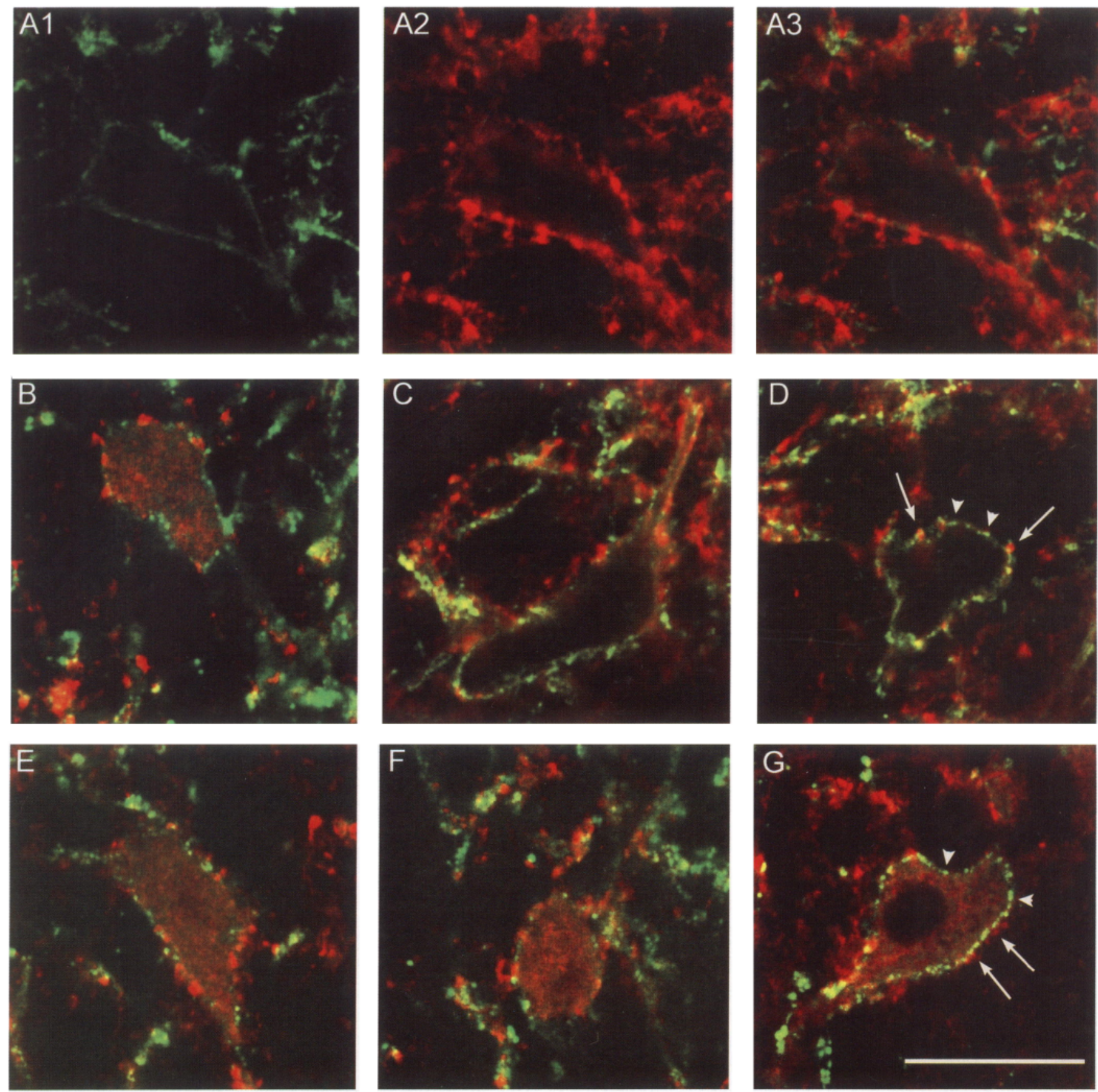

Figure 10. Synaptic and extrasynaptic AChR surface clusters are found in both embryonic and adult SpL. A shows an optical section of a single $\mathrm{SpL}$ neuron. Al shows surface AChR clusters stained with mAb 35 (green) while $A 2$ shows synaptic boutons stained with mAb $10 \mathrm{~h}$ (red). A3 is a color merge of $A 1$ and $A 2$; this merged image allows comparison of the relative location of the AChR surface clusters and synaptic boutons. $B$ $D$ show additional merged images of AChR clusters (green) and synaptic boutons (red) from other embryonic SpL neurons. These figures illustrate that some AChR clusters are at synaptic sites $(D$, arrows) while many AChR clusters are extrasynaptic $(D$, arrowheads). $E-G$ show merged images of AChR clusters and synaptic boutons from adult SpL. Again, some AChR clusters are synaptic $(G$, arrows) and many clusters are extrasynaptic ( $G$ arrowheads). Scale in $G, 20 \mu \mathrm{m}$.

(Nicoll et al., 1990); exceptions include the spinal cord motor neuron-Renshaw cell synapse (Eccles et al., 1954) and retinal amacrine cell-ganglion cell synapses (Masland et al., 1984). Similarly, there have been few instances where AChRs have been shown to be located at postsynaptic sites within the CNS (Schröder et al., 1989). The AChR subunit-LIs expressed in the SpL can only mediate synaptic transmission if they are clustered at cholinergic synapses. In our experiments on embryos only
$25 \%$ of the clusters of $\alpha 5$ and $\beta 2$ AChR-LI were associated with immunocytochemically visualized synaptic boutons. The numerous extrasynaptic AChR clusters are unlikely to be an artifact due to incomplete staining of vesicle antigen, because many SV2 sites were strongly labeled (Fig. 10). Therefore, these clusters of AChR subunit-LI truly may be extrasynaptic. Extrasynaptic AChR clusters have been found elsewhere (Jacob and Berg, 1983; Jacob et al., 1984; Sargent and Pang, 1989; Sargent 
et al., 1989; see also Smiley and Yazulla, 1990; Baude et al., 1993; Liu et al., 1994; Smiley et al., 1994). The further reduction in the fraction of clusters of AChR-LI at synaptic sites in the adult implies that the preponderance of extrasynaptic AChR clusters in the embryo is not a developmental artifact, stemming from the fact that the proper connections between the SLu and SpL are not yet established.

The structural diversity of neuronal AChRs has been studied in the CNS, where various techniques have detected $\alpha 2, \alpha 3, \alpha 4$, $\alpha 5, \alpha 7, \alpha 8, \beta 2$, and $\beta 4$ subunits (reviewed in Deneris et al., 1991; Lukas and Bencherif, 1992; Role, 1992; Patrick et al., 1993; Sargent, 1993). The $\alpha 7$ subunit appears in at least two classes of AChRs in chicken brain; those that contain the $\alpha 8$ subunit and those that lack it (Schoepfer et al., 1990). In chick retina, there appear to be AChRs that contain the $\alpha 8$ subunit but not the $\alpha 7$ subunit (Keyser et al., 1993). The $\alpha 7$ and $\alpha 8$ subunits, which account for virtually all high-affinity $\alpha$-Bgt binding in chicken brain, apparently do not associate with any of the other known $\alpha$ or $\beta$ subunits (Schoepfer et al., 1990, Conroy et al., 1992). In chicken brain, the $\alpha 5$ subunit associates with the $\alpha 4$ subunit and separately with the $\alpha 3$ subunit; some AChRs appear to contain $\alpha 3, \alpha 4$, and $\alpha 5$ subunits (Conroy et al., 1992). Some of these AChR classes may also contain the $\beta 2$ subunit (Whiting et al., 1987; Conroy et al., 1992; see also Flores et al., 1992). Thus, some neuronal AChRs contain at least four unique subunits and may therefore be as complex as muscle AChRs (Conroy et al., 1992).

Our experiments on the $\mathrm{SpL}$ extend the analysis of $\mathrm{AChR}$ structural diversity to the level of a single nucleus and suggest that different neurons within the same nucleus may assemble AChRs having different subunits. In the SpL, $\alpha 5$-LI and $\beta 2$-LI are found in most neurons and could be components of the same AChR (Conroy et al., 1992). In contrast, neurons containing $\alpha 7$ LI as well as both $\alpha 5$-LI and $\beta 2$-LI (Fig. 6) probably do not assemble these threc subunits into a single AChR type, since $\alpha 7$ subunits do not coassemble detectably with $\alpha 5$ or $\beta 2$ subunits in chicken brain (Schoepfer et al., 1990; Conroy et al., 1992). SpL neurons expressing $\alpha 7$-LI and $\alpha 8$-LI may form AChRs containing both subunits (Schoepfer et al., 1990). No $\alpha 3-$ LI is found in the $\mathrm{SpL}$, so we assume that $\alpha 3$-containing AChRs (Conroy et al., 1992) are accounted for by other brain regions.

The diverse neuronal types based on AChR subunit-LI are consistent with the diverse pharmacology reported in the SpL by Weaver et al. (1994), who found that nicotinic responses of some $\mathrm{SpL}$ neurons were blocked potently by the AChR antagonist trimethaphan, while responses of other neurons were not affected. Thus, both immunocytochemical and pharmacological studies suggest that $\mathrm{AChR}$ subunit composition within the $\mathrm{SpL}$ may differ on a neuron-to-neuron basis. In contrast, AChR subunit expression in the chicken ciliary ganglion is apparently uniform: virtually all neurons express each of the subunits found in the ganglion as a whole (Boyd et al., 1988; Corriveau and Berg, 1993; Sargent and Wilson, 1994). Ciliary ganglion neurons may serve fewer functions than $\mathrm{SpL}$ neurons and may not require such a diverse group of nicotinic AChRs.

It is notable that we obtained different results using three mAbs specific for the $\alpha 7$ subunit (Schoepfer et al., 1990); mAbs 306 and 318 produced staining of a small population of SpL neurons, but mAb 319 did not. This discrepancy may be related to differences in specificity, since the eptitope for mAbs 306 and 318 is largely nonoverlapping with that for mAb 319 (McLane et al., 1992). In contrast to the results in the SpL, all three anti- $\alpha 7 \mathrm{mAbs}(306,318,319)$ stain neurons in the ciliary ganglion (not shown). The tissue differences in the binding of 319 may be explained if the epitope for 319 is exposed in fixed ciliary ganglia, but buried in the SpL. Perhaps a cytoplasmic membrane protein in the SpI. (similar to the $43 \mathrm{~K}$ protein of muscle) is crosslinked to $\alpha 7$ by the fixative, resulting in occlusion of this epitope.

The appearance of $\alpha 4$-LI in the 14 week SpL implies that developmental regulation of this subunit is different from other AChR-LIs. The $\alpha 4$ mRNA is abundant in $1 \mathrm{~d}$ posthatch chicks (Morris et al., 1990). It is possible that the $\alpha 4$ subunit is suddenly expressed after hatching, as the visuomotor system of the chick is first used. Since the SpL is part of the avian visuomotor system (Reiner et al., 1982), it is possible that these changes are visually driven. It is notable that Keyser et al. (1993) have described changes in the relative amounts of $\alpha 7$ - and $\alpha 8$-LI in the chicken retina at the time of hatching.

A presynaptic function for $\mathrm{AChRs}$ in the optic tectum would be suggested if AChR subunits were transported to the tectum from the $\mathrm{SpL}$. There is pharmacological evidence for presynaptic nicotinic AChRs in the CNS, although in very few instances do we have a solid understanding of either their functional role or the source of ACh (see Sargent, 1993). The $\beta 2$ subunit is a candidate for transport from the SpL to the optic tectum, since it is present in most neurons in the $\mathrm{SpL}$ and in a layer of the optic tectum that receives an SpL projection, the SGC. It seems unlikely that the $\beta 2$-LI within the SGC arises intrinsically, since few $\beta 2$-immunoreactive neuronal cell bodies are present there. To confirm that the $\beta 2-\mathrm{LI}$ in the SGC of the optic tectum is transported from the $\mathrm{SpL}$, additional experiments would be needed, such as metabolic labeling and immunoprecipitation (Henley et al., 1986).

The $\alpha 5$ subunit is another candidate for transport from the SpL to the optic tectum (Swanson et al., 1983). However, while $\alpha 5$-LI is present within the optic tectum in posthatch chicks as well as 14 week chickens (Swanson et al., 1983; Fig. 9A), we failed to find $\alpha 5$-LI in the optic tectum at late embryonic stages, as previously observed by Swanson et al. (1983). These results suggest that $\alpha 5$ subunit expression in the optic tectum is developmentally regulated. If the $\alpha 5$ subunit in the SGC originates from $\mathrm{SpL}$ projections, then these projections may not form until after hatching. Alternatively, the projections may preexist, and the axonal transport of the $\alpha 5$ subunit may be developmentally regulated.

The argument that the $\alpha 7$ and $\alpha 8$ subunits may be transported from the SpL to the optic tectum is less compelling than for the $\beta 2$ and $\alpha 5$ subunits, since neuronal cell bodies immunoreactive for the $\alpha 7$ and $\alpha 8$ subunits are present in the optic tectum and may account for the punctate staining in the SGC layer (Fig $8 B, C)$.

Another source of AChR subunit-LI could be the retinal ganglion cells that project to the optic tectum. Although retinal ganglion cells are immunoreactive for $\beta 2, \alpha 3, \alpha 5, \alpha 7$, and $\alpha 8$ subunits (Whiting et al., 1991; Britto et al., 1992b; Anand et al., 1993; Keyser et al., 1993) and may transport some or all of these subunits to the optic tectum (Britto et al., 1992a), the vast majority of retinal ganglion cells do not project to the SGC, but rather to more superficial layers (Crossland et al., 1973, 1974).

In conclusion, our experiments reveal a surprising diversity of neuron types based on expression of AChR subunit-LIs in the $\mathrm{SpL}$, and they identify subunits that might be targeted to the optic tectum, where they could act as presynaptic AChRs. The 
observed degree of diversity exceeds what would be expected if AChRs in the SpL serve solely a classical receptor role by responding to $\mathrm{ACh}$ focally released from presynaptic terminals. Our experiments also demonstrate that most AChR clusters on $\mathrm{SpL}$ neurons are extrasynaptic. This constitutes further evidence that AChRs do not serve a classical role in the SpL.

\section{References}

Anand R, Conroy WG, Schoepfer R, Whiting P, Lindstrom J (1991) Neuronal nicotinic acetylcholine receptors expressed in Xenopus oocytes have a pentameric quaternary structure. J Biol Chem 266: $11192-11198$.

Anand R, Peng X, Ballesta I.I, Lindstrom J (1993) Pharmacological characterization of $\alpha$-bungarotoxin-sensitive acetylcholine receptors immunoisolated from chick retina: contrasting properties of $\alpha 7$ and $\alpha 8$ subunit-containing subtypes. Mol Pharmacol 44:1046 1050.

Baude A, Nusser, Z, Roberts JDB, Mulvihill E, McIlhinney J, Somogyi $P$ (1993) The metabotropic glutamate receptor (mGluR $1 \alpha$ ) is concentrated at presynaptic membrane of neuronal subpopulations as detected by immunogold reaction. Neuron 11:771-787.

Boyd RT, Jacob MH, Couturier S, Ballivet M, Berg DK (1988) Expression and regulation of neuronal acetylcholine receptor mKNA in chick ciliary ganglia. Neuron 1:495-502.

Britto LR, Keyser KT, Lindstrom JM, Karten HJ (1992a) Immunohistochemical localization of nicotinic acetylcholine receptor subunits in the mesencephalon and diencephalon of the chick (Gallus gallus). $\mathbf{J}$ Comp Neurol 317:325-340.

Britto LRG, Hamassaki-Britto DE, Ferro ES, Keyser KT, Karten HJ, Lindstrom JM (1992b) Neurons of the chick brain and retina expressing both $\alpha$ bungarotoxin sensitive and $\alpha$ bungarotoxin insensi tive nicotinic acetylcholine receptors: an immunohistochemical analysis. Brain Res 590:193-200.

Buckley K, Kelly RB (1985) Identification of a transmembrane glycoprotein specific for secretory vesicles of neural and endocrine cells. J Cell Biol 100:1284-1294.

Conroy WG, Vernallis AB, Berg DK (1992) The $\alpha 5$ gene product assembles with multiple acetylcholine receptor subunits to form distinctive receptor subtypes in brain. Neuron 9:679-691.

Corriveau RA, Berg DK (1993) Coexpression of multiple acetylcholine receptor genes in neurons: quantitation of transcripts during development. II Neurosci 13:2662-2671.

Crossland WJ, Cowan WM, Kelly JP (1973) Observation on the transport of radioactively labeled proteins in the visual system of the chick. Brain Res 56:77 105.

Crossland WJ, Cowan WM, Rogers LA, Kelly JP (1974) The specification of the retino-tectal projection in the chick. J Comp Neurol 155:127-164.

Deneris ES, Connolly J, Rogers SW, Duvoisin R (1991) Pharmacological and functional diversity of neuronal nicotinic acetylcholine receptors. 'Irends Pharmacol Sci 12:34-40.

Eccles JM, Fatt P, Koketsu K (1954) Cholinergic and inhibitory synapses in a pathway from motor-axon collaterals to motoneurons. $\mathbf{J}$ Physiol (Lond) 126:524-562.

Elgoyhen AB, Johnson DS, Boulter J, Vetter DE, Heinemann S (1994) $\alpha 9$ : an acetylcholine receptor with novel pharmacological properties expressed in rat cochlear hair cells. Cell 79:705-715.

Flores CM, Rogers SW, Prabreza LA, Wolfe BB, Keller KJ (1992) A subtype of nicotinic cholinergic receptor in rat brain is comprised of $\alpha-4$ and $\beta-2$ subunits and is up-regulated by chronic nicotine treatment. Mol Pharmacol 41:31-37.

Giloh H Sedat JW (1982) Fluorescence microscopy: reduced photobleaching of rhodamine and fluorescein protein conjugates by n-propyl gallate. Science 217:1252-1255.

Hall LW, Sanes JR (1993) Synaptic structure and development: the neuromuscular junction. Neuron 10:99-121.

Haselbeck RC, Conroy WG, Romano SJ, Berg DK (1994) Expression of neuronal ACh receptor genes in transfected HEK-293 cells. Soc Neurosci Abstr 20:466.11.

Henley JM, Lindstrom JM, Oswald RE (1986) Acetylcholine receptor synthesis in retina and transport to optic tectum in goldfish. Science 232:1627-1629.

Jacob MH, Berg DK (1983) The ultrastructural localization of alphabungarotoxin binding sites in relation to synapses on chick ciliary ganglion neurons. J Neurosci 3:260-271.
Jacob MH, Berg DK, Lindstrom JM (1984) Shared antigenic deter minants between Electrophorus acetylcholine receptor and a synaptic component on chicken ciliary ganglion neurons. Proc Natl Acad Sci USA 81:3223-3227.

Keyser KT, Britto, LRG, Schoepfer R, Whiting P, Cooper J, Conroy W, Brzozowska-Prechtl A, Karten HJ, Lindstrom J (1993) Three subtypes of $\alpha$-bungarotoxin-sensitive nicotinic acetylcholine receptors are expressed in chick retina.. J Neurosci 13:442-454.

Kuenzel WJ, Mason M (1988) A stereotaxic atlas of the brain of the chick (Gallus domesticus). Baltimore: Johns Hopkins UP.

Lindstrom J, Schoepfer R, Whiting P (1987) Molecular studies of the neuronal acetylcholine receptor family. Mol Neurobiol 1:281-337.

Liu H, Brown JL, Jasmin L, Maggio JE, Vigna SR, Mantyh PW, Basbaum AI (1994) Synaptic relationship between substance P and the substance $P$ receptor: light and electron microscopic charactcrization of the mismatch between neuropeptides and their receptors. Proc Natl Acad Sci USA 91:1009-1013.

Lukas RJ, Bencherif M (1992) Heterogeneity and regulation of nicotinic acetylcholine receptors. Int Rev Neurobiol 34:25-131.

Masland RH, Mills JW, Cassidy C (1984) The function of acetylcholine in the rabbit retina. Proc $\mathrm{R}$ Soc Lond [Biol] 223:121-139.

Matter J-M, Matter-Sadzinski L, Ballivet M (1990) Expression of neuronal nicotinic acetylcholine receptor genes in the developing chick visual system. EMBO J 9:1021-1026.

McLane KE, Wu X, Lindstrom JM, Conti-Tronconi BM (1992) Epitope mapping of polyclonal and monoclonal antibodies against two $\alpha$-bun garotoxin a subunits from neuronal nicotinic receptors. J Neuroimmunol 38:115-128.

Morris BJ, Hicks AA, Wisden W, Darlison MG, Hunt SP, Barnard EA (1990) Distinct regional expression of nicotinic acetylcholine receptor genes in chick brain. Mol Brain Res 7:305-315.

Mulle C, Vidal C, Benoit P, Changeux J-P (1991) Existence of different subtypes of nicotinic acetylcholine receptors in the rat habenulo-interpeduncular system. J Neurosci 11:2588-2597.

Nicoll RA, Malenka RC, Kauer JA (1990) Functional comparison of neurotransmitter receptor subtypes in mammalian central nervous system. Physiol Rev 70:513-565.

Patrick J, Séguéla P, Vernino A, Amador M, Luetje C, Dani JA (1993) Functional diversity of neuronal nicotinic acetylcholine receptors. Prog Brain Res 98:113-120.

Pugh PC, Corriveau RA, Conroy, WG, Berg, DK (1995) Novel subpopulation of neuronal acetylcholine receptors among those binding alpha-bungarotoxin. Mol Pharm 47:717-725.

Reiner A, Brecha NC, Karten HJ (1982) Basal ganglia pathways to the tectum: The afferent and efferent connections of the lateral spiriform nucleus of pigeon. J Comp Neurol 208:16-36.

Role LW (1992) Diversity in primary structure and function of neuronal nicotinic acetylcholine receptor channels. Curr Opin Neurosci 2:254-262.

Sargent PB (1993) The diversity of neuronal nicotinic acetylcholine receptors. Annu Rev Neurosci 16:403-443.

Sargent PB (1994) Double-label immunofluorescence with the laser scanning confocal microscope using cyanine dyes. Neuroimage $1: 288-295$.

Sargent PB, Pang DZ (1989) Acetylcholine receptor-like molecules are found in both synaptic and extrasynaptic clusters on the surface of neurons in the frog cardiac ganglion. J Neurosci 9:1062-1072.

Sargent PB, Pike SH, Nadel DB, Lindstrom JM (1989) Nicotinic acetylcholine receptor-like molecules in the retina, retino-tectal pathway, and optic tectum of the frog. J Neurosci 9:565-573.

Sargent PB, Wilson HL (1994) Distribution of nicotinic acetylcholine receptor subunit immunoreactivities on the surface of chick ciliary ganglion neurons. In: International symposium on nicotine: the effects of nicotine on biological systems II (Clarke PBS, Quik M, Thurau $\mathrm{K}$, Adlkofer $\mathrm{F}$, eds), abstract $\mathrm{P} 1$. Boston: Birkhauser.

Schoepfer R, Conroy WG, Whiting P, Gore M, Lindstrom J (1990) Brain $\alpha$-bungarotoxin binding protein cDNAs and mAbs reveal subtypes of this branch of the ligand-gated ion channel gene superfamily. Neuron 5:35-48.

Schröder H, Zilles K, Maelicke A, Hajós F (1989) Immunohisto- and cytochemical localization of cortical nicotinic cholinoceptors in rat and man. Brain Res 502:287-295.

Sorenson EM, Parkinson D, Dahl JL, Chiappinelli VA (1989) Immunohistochemical localization of choline acetyltransferase in the chicken mesencephalon. J Comp Neurol 281:641-657. 
Sorenson EM, Chiappinelli VA (1990) Intracellular recording in avian brain of a nicotinic response that is insensitive to K-bungarotoxin. Neuron 5:307-315.

Smiley JF, Yazulla S (1990) Glycinergic contacts in the outer plexiform layer of the Xenopus laevis retina characterized by antibodies to glycine, GABA, and glycine receptors. J Comp Neurol 299:375-388.

Smiley JF, Levey AI, Ciliax BJ, Goldman-Rakic PS (1994) D dopamine receptor immunoreactivity in human and monkey cerebral cortex: predominant and extrasynaptic localization in dendritic spines. Proc Natl Acad Sci USA 91:5720-5724.

Swanson LW, Lindstrom J, Tzartos S, Schmued L, O'Leary D, Cowan WM (1983) Immunohistochemical localization of monoclonal antibodies to the nicotinic acetylcholine receptor in chick midbrain. Proc Natl Acad Sci USA 80:4532-4536.

Tzartos SJ, Rand DE, Einarson BL, Lindstrom JM (1981) Mapping of surface structures of electrophorus acetylcholine receptor using monoclonal antibodies. J Biol Chem 256:8635-8645.

Ullian EM, Sargent PB (1994) Cellular diversity in the expression of nicotinic acetylcholine receptor subunits in the chick central nervous system. In: International symposium on nicotine: the effects of nicotine on biological systems II (Clarke PBS, Quik M, Thurau K, Adlkofer F, eds), abstract P1. Boston: Birkhauser.
Vernallis AB, Conroy WG, Berg DK (1993) Neurons assemble acetylcholine receptors with as many as three kinds of subunits while maintaining subunit segregation among receptor subtypes. Neuron $10: 451-464$.

Wada E, Wada K, Boulter J, Deneris E, Heinemann S, Patrick J, Swanson LW (1989) Distribution of alpha2, alpha3, alpha4, and beta2 neuronal nicotinic receptor subunit mRNAs in the central nervous system: a hybridization histochemical study in the rat. J Comp Neurol 284:314-335.

Weaver WR, Wolf KM, Chiappinelli VA (1994) Functional heterogeneity of nicotinic receptors in the avian lateral spiriform nucleus detected with trimethaphan. Mol Pharmacol 46:993-1001.

Whiting PJ, Lindstrom J (1986a) Purification and characterization of a nicotinic acetylcholine receptor from chick brain. Biochemistry 25 : 2082-2093.

Whiting PJ, Lindstrom J (1986b) Pharmacological properties of immuno-isolated neuronal nicotinic receptors. J Neurosci 6:3061-3069.

Whiting PJ, Liu R, Morley BJ, Lindstrom JM (1987) Structurally different neuronal nicotinic acetylcholine receptor subtypes purified and characterized using monoclonal antibodies. J Neurosci 7:4005-4016.

Whiting PJ, Schoepfer R, Conroy WG, Gore MJ, Keyser KT, Shimasaki S, Esch F, Lindstrom JM (1991) Expression of nicotinic acetylcholine subtypes in brain and retina. Mol Brain Res 10:61-70. 